\title{
LAS ESTRATEGIAS TERRITORIALES PARA LA TRANSFORMACIÓN PRODUCTIVA. REFLEXIÓN DESDE EL CASO DEL PAÍS VASCO ${ }^{1}$
}

\author{
Autor: Mikel Navarro Arancegui ${ }^{2}$ \\ Orkestra-Instituto Vasco de Competitividad y DBS-Universidad de Deusto
}

\section{Resumen}

El artículo revisa la reciente literatura sobre estrategia territorial, mostrando sus orígenes, en qué se diferencia la estrategia empresarial y territorial, los rasgos distintivos (prioridades temáticas y procesos de descubrimiento emprendedor) de las estrategias de invención e innovación para la especialización inteligente y las vías o mecanismos (modernización, expansión, fundación radical y combinación) por las que tiene lugar la transformación productiva que toda estrategia territorial debe perseguir. Tras ello, para ilustrar como todo ello tiene lugar y extraer lecciones que puedan servir de guía para el desarrollo de estrategias territoriales de transformación productiva por las regiones españolas, se analiza la aplicación ha-

\footnotetext{
${ }^{1}$ El autor desea reconocer el apoyo proporcionado por la Comisión Europea (FP7 SSH.2012.1.1-3), bajo la subvención número 320131.

${ }^{2}$ mnavarro@orkestra.deusto.es
} 
bida de estrategias de desarrollo en el País Vasco desde comienzos de los años 80, profundizando en particular en su actual estrategia de especialización inteligente.

Palabras clave: estrategia territorial; especialización inteligente; diversificación; prioridades verticales; País Vasco

\title{
Territorial strategies for productive transformation. Reflection from the case of the Basque Country
}

\begin{abstract}
This paper reviews the recent literature on territorial strategy, showing its origins, the differences between business and territorial strategies, the distinctive features of the research and innovation smart specialisation strategies (i.e. the thematic priorities and entrepreneurial discovery processes) and the ways and mechanisms (modernization, extending, radical foundation and combination) for the transformation of the production structure that all territorial strategies should try to achieve. Then, in order to illustrate all this and draw some lessons that could guide the Spanish regions' territorial strategies for the transformation of their production systems, the paper analyses the Basque Country's development strategies implemented since the early eighties, and particularly its current smart specialisation strategy.
\end{abstract}

Key words: territorial strategy; smart specialization; diversification; vertical priorities; Basque Country.

\section{INTRODUCCIÓN}

Prácticamente todos los analistas de la aguda crisis que sacude a España desde 2008 coinciden en que la mayor gravedad de la crisis española se debía en gran parte al equivocado modelo de crecimiento seguido por la economía española. Ese modelo había llevado a que en el período 2000-2007 la productividad aparente del trabajo promedio de la economía española, en lugar de crecer, decreciera a una tasa anual del 0,7\%; a que el déficit de la balanza por cuenta corriente alcanzara en 2007 el 10\% del PIB; y a que la industria manufacturera (sector clave desde el punto de vista de la I+D, la exportación, la cualificación media del operario, la productividad 
y capacidad de arrastre del resto de la economía) supusiera solo un 15\% del VAB del total de la economía. El caso de la Comunidad Autónoma del País Vasco (por abreviar, solo País Vasco en lo sucesivo) muestra, sin embargo, que tales rasgos no se derivan insoslayablemente del contexto institucional de la economía española. En efecto, aun compartiendo con las restantes comunidades autónomas españolas gran parte de ese contexto institucional nacional, la economía vasca experimentó en el período 2000-2007 un crecimiento anual de la productividad aparente del trabajo del 0,9\%, un superávit en su balanza de bienes y servicios con el extranjero del 1,9\% del PIB y un peso del VAB manufacturero superior al $25 \%$ del total de su economía.

Lo que resulta todavía más preocupante es que hay señales de que la salida de la recesión, qué parece innegable que en 2014-2015 está teniendo lugar, no va acompañada por signos de que la economía española haya aprovechado la crisis para iniciar un cambio de modelo. Así, por ejemplo, en 2014 la economía española ha retornado a aumentos altos del empleo $(1,26 \%)$, pero nuevamente acompañados de crecimientos casi nulos de la productividad (0,2\%). Es decir, la fuerte creación de empleos que está teniendo en la salida de la crisis, al igual que pasaba antes de la entrada en aquella, se concentra en actividades de bajo valor añadido. Una situación distinta acontece en el caso del País Vasco, en el que, aunque el empleo crece a un menor ritmo $(0,3 \%)$ en $2014,{ }^{3}$ tal empleo parece de mayor calidad, como muestra el hecho de que la productividad haya crecido $(1,0 \%)$.

Como más adelante se señala, uno de los factores que explica ese comportamiento diferencial del País Vasco es que, aprovechando el notable nivel de competencias que recuperan las administraciones públicas vascas desde comienzos de los años ochenta, el Gobierno Vasco pone en marcha estrategias territoriales de desarrollo que, aunque a contracorriente en aquel tiempo, en el que no estaban de moda ni las políticas industriales y ni que el gobierno apostara por determinadas áreas determinadas, anticipan bastantes de los rasgos que luego caracterizarán a las llamadas estrategias de investigación e innovación para la especialización inteligente (conocidas como RIS3, por su denominación inglesa: Research and Innovation Smart Specialisation Strategies).

Este artículo tiene por objetivo, precisamente, estudiar la novedad que suponen las llamadas RIS3 dentro de las políticas y la literatura, y en particular su apuesta a favor de fijar prioridades temáticas o verticales. Como más adelante se verá, toda estrategia de desarrollo inteligente debe perseguir la transformación económica, pues el desarrollo no es solo una cuestión meramente cuantitativa (¡cuánto crece la economía!), sino que ante todo es una cuestión cualitativa (¡cómo se transforma la estructura económica!). La literatura de la RIS3 muestra que esa diversificación y mejora de la estructura productiva tiene lugar mediante varios mecanismos, cuya importancia relativa varía de unas prioridades o actividades a otras. En todo caso, esa fijación de prioridades temáticas y los procesos

${ }^{3}$ Lo que en parte se explica por la también por la muy inferior pérdida de empleo habida entre 2008 y 2013. 
de transformación productiva a ellos ligados no pueden ser fruto exclusivo de la actividad del gobierno, pues este no tiene ni los conocimientos ni las capacidades para llevarlos adelante por sí solo, sino que tienen que ser fruto de un "proceso de descubrimiento emprendedor", en el que deberían estar implicados los diferentes tipos de actores que componen la llamada "cuádruple hélice".

Para ilustrar y ver cómo todo ello puede tener en la realidad, se ha elegido el caso del País Vasco. En efecto, la literatura de benchmarking territorial muestra que, aunque siempre se puede aprender del análisis de otras experiencias, ese aprendizaje conducirá a lecciones más aplicables para el territorio en el caso de que este se compare, en primer lugar, con realidades comparables (es decir, que compartan en mayor medida sus condiciones estructurales de partida); y en segundo lugar, que dentro de esas realidades comparables, se elija a aquellas que han alcanzado un mayor éxito, puesto que, nuevamente, aunque siempre se puede aprender de todos, en principio habrá más cosas que aprender de aquellos que lo han hecho mejor (véase Navarro y otros, 2012). Pues bien, en la medida que el País Vasco comparte gran parte de su historia y de sus instituciones con el resto de España, resulta una realidad más comparable para las regiones que componen esta; e igualmente, son múltiples los indicadores (p.e. el PIB per cápita o la tasa de desempleo) que muestran que el País Vasco puede considerarse como una de las regiones españolas de mejor desempeño.

Así pues, tras esta breve introducción, el artículo se organiza de la siguiente manera. En el siguiente apartado se expondrán una serie de cuestiones clave de la literatura de estrategias territoriales de desarrollo: cómo han surgido las estrategias territoriales, qué singularidades presentan con respecto a las estrategias empresariales, y qué vías contemplan para llevar adelante la diversificación y mejora de la estructura productiva. A continuación pasaremos a analizar las estrategias de transformación productiva en el País Vasco: cómo se han aplicado y han ido evolucionando desde primeros de los años 80 , y en qué consiste la estrategia de especialización inteligente del País Vasco en la actualidad. Esto es, qué prioridades temáticas se han elegido y por qué, cómo han operado las diferentes vías de transformación productiva en cada una de sus prioridades y cuáles han sido los procesos por las que se han fijado y llevado adelante tales prioridades temáticas, y el papel de los diferentes agentes en aquellas.

\section{LAS ESTRATEGIAS DE TRANSFORMACIÓN PRODUCTIVA}

\subsection{Aparición de las estrategias territoriales}

Desde comienzos de la década de los 80 ha venido teniendo lugar una evolución confluyente en las literaturas y políticas relativas a tres importantes ámbitos: la industrial, la tecnológica y la de desarrollo regional. En la literatura y política 
industrial las claves de la competitividad dejan de verse ligadas, mayormente, a factores macro y al apoyo a grandes campeones nacionales, y la atención pasa a orientarse hacia los factores micro y los clústeres. En la literatura y política tecnológica, superando los modelos lineales de impulso a la I+D, se toma conciencia de que la innovación es un proceso social en el que la interacción es fundamental; de que la innovación requiere, además de conocimiento explícito o formal, conocimiento de carácter tácito; y de que la I+D es solo una de las actividades innovadoras que puede llevar a la innovación, y que junto a un modo de innovar y aprender basado en la ciencia, tecnología e innovación (modo STI, por Science, Technology and Innovation), hay otro basado en el innovar y aprender gracias al hacer, usar e interactuar (modo DUI, por "learning by doing, by using and interacting"). Y, por último, la literatura y política de desarrollo regional deja de creer que se puede superar el menor desarrollo de ciertas regiones y territorios mediante la captación de inversiones exteriores y transferencias compensatorias desde las regiones más avanzadas, y se toma conciencia de que lo fundamental es crear las bases para que tenga lugar un proceso de desarrollo endógeno (Navarro, 2009).

\section{Figura 1. Proceso de confluencia en la literatura y políticas industriales, tecnológicas y de desarrollo regional}

(Entorno micro general y clústeres)

Literatura y

política industrial

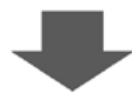

Territorio e innovación

\section{Literatura y política tecnológica}

(Interacción, conocimiento tácito e innovación no basada en I+D)

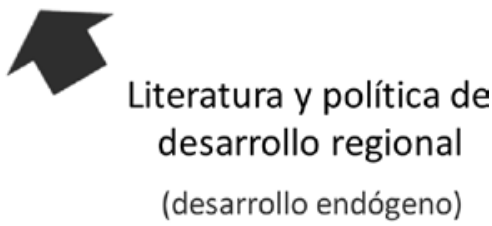

(desarrollo endógeno)

Fuente: elaboración propia.

La confluencia de estos tres ámbitos pivota sobre dos factores esenciales que actúan como vínculo entre ellos: el territorio y la innovación. En efecto, si bien el plano macro opera básicamente a nivel nacional o supranacional, el plano preferible para manejar las políticas micro es generalmente el regional. Asimismo, 
en la medida en que se constata que las interacciones, la transmisión de conocimiento tácito y la innovación no tecnológica (e incluso la tecnológica basada en actividades distintas de la I+D) son capitales, la proximidad y los planos regional y local ganan relevancia en las políticas de innovación. Por último, el desarrollo regional, en tanto que se entiende que ha de ser de carácter principalmente endógeno, resulta muy dependiente de las variables ligadas al propio territorio.

En cuanto al segundo factor que actúa como vínculo: la innovación, hay una reorientación generalizada de las políticas industriales y de competitividad, que pasan de hacer descansar las ventajas competitivas en los factores productivos tradicionales a entender que la competitividad es equiparable en última instancia a la "productividad", y que detrás de los crecimientos sostenidos de esta se encuentra la innovación. Las políticas de ciencia y tecnología pasan a denominarse de innovación, no sólo por una comprensión más amplia de los factores que influyen en el desarrollo económico, sino también porque se toma conciencia de que la I+D no lleva automáticamente a la innovación y de que lo que realmente importa para el desarrollo económico y para hacer frente a los retos sociales es innovar. Por último, el desarrollo endógeno deja de verse dependiente del "cemento y ladrillo" (infraestructuras físicas) y se asocia cada vez más al desarrollo de capacidades innovadoras en el territorio (tales como las infraestructuras inteligentes, la formación de su población y el gasto en innovación).

Todo esto condujo a la eclosión, en la década de los 80 y los 90, de toda una serie de corrientes (los distritos industriales, los milieu innovadores, los sistemas productivos locales, las regiones que aprenden, los distritos tecnológicos, entre otras) nucleadas en torno al análisis interrelacionado de esos dos factores: territorio e innovación (Moulart y Sekia, 2003). Entre todas ellas hubo una corriente que destacó en términos de popularidad y aceptación por parte de las instituciones o agentes responsables de las políticas de desarrollo regional: la de los sistemas regionales de innovación. Por estos se entendía "la infraestructura institucional que apoya a la innovación en la estructura productiva de una región" (Asheim y Gertler, 2005, p. 299).

Fue esta corriente la que inspiró fundamentalmente a la Comisión Europea en su impulso a las estrategias regionales de innovación en los años noventa, denominadas en aquel entonces estrategias RIS (por su nombre inglés: Regional Innovation Strategies). En general, en estas escuelas que ligaban territorio e innovación se fue compartiendo la idea de que los territorios debían poseer estrategias tendentes a la construcción de ventajas competitivas, a partir de su particular configuración de recursos y capacidades, y de las tendencias existentes en el entorno (Asheim y otros, 2006).

\subsection{Singularidad de las estrategias de desarrollo territorial}

Al igual que en otros conceptos (por ejemplo, el de competitividad) importados acríticamente del ámbito de la Dirección o Economía de Empresas 
a la economía y el territorio, inicialmente los analistas no se plantearon las adaptaciones que el concepto de estrategia debía experimentar para aplicarse en su nuevo ámbito de aplicación. Pero las diferencias son evidentes, y al igual que economistas como Krugman habían ironizado sobre las contradicciones que plantean ese tipo de importaciones acríticas (por ejemplo, cuando Krugman pregunta qué país, a semejanza de lo que ocurriría en toda empresa, ha cerrado por no ser competitivo), hay quienes, ironizando sobre la importación del término estrategia al ámbito del territorio, empiezan a preguntar a qué importante agente le han despedido o expulsado del territorio por seguir unas actuaciones o propugnar unas estrategias particulares no coincidentes con las aprobadas en el territorio, tal como ocurriría a cualquier director o persona que actúe o se posicione claramente en contra de la estrategia establecida y aprobada por su empresa.

Los intentos más elaborados de adaptación del concepto de estrategia al ámbito territorial se encuentran en Aranguren y otros (2012), Navarro y otros (2014) y Valdaliso y Wilson (2015). En tales trabajos se expone que tanto en términos de los objetivos (o para qué), como del contenido (o qué) y de los procesos (los "cómo" y "por quién"), la estrategia territorial difiere de la empresarial.

- En cuanto a los objetivos, frente a la maximización del valor de los accionistas (o, desde una visión más amplia, del conjunto de agentes o stakeholders de la empresa) que plantea la estrategia empresarial, la estrategia del territorio puede plantear una combinación de competitividad económica, inclusión social y sostenibilidad medioambiental.

- En lo relativo a su contenido, la estrategia empresarial se caracteriza por las respuestas que da a una serie de preguntas relativas al posicionamiento de la empresa en el mercado y a los recursos y capacidades que persigue desarrollar, mientras que la territorial debe plantearse otras preguntas diferentes: qué actividades o áreas temáticas se impulsarán, qué activos o funciones se desarrollarán para tener éxito en aquellas, qué tipos de empresas y organizaciones se primarán, qué tipo de relaciones y conexión tendrá el territorio con otros territorios y agentes externos, y qué articulación interna de sus agentes y cohesión territorial se perseguirá.

- Pero, aun habiendo claras diferencias entre los objetivos y contenidos de las estrategias empresariales y territoriales, sin duda las mayores diferencias entre las estrategias territoriales y empresariales tienen lugar en los procesos por los que se diseñan, desarrollan y evalúan unas y otras. El territorio es una realidad mucho más compleja y plural que la empresa, con relaciones de poder, gobernanza y liderazgo más diversas y complicadas, que requiere en última instancia de procesos participativos más profundos y variados. 
Figura 2. Diferencias entre estrategia empresarial y territorial

\section{EMPRESA}

1. OBJETIVOS

2. CONTENIDO

- Posicionamiento en el mercado

- Qué productos

- Qué clientes y necesidades

- Qué acceso

- Qué recursos y capacidades internos

\section{PROCESO}

Más o menos participativo, pero obligatorio para todos los miembros de la empresa

\section{TERRITORIO}

1. OBJETIVOS

2. CONTENIDO

- Qué áreas (económicas, científicas...)

- Qué activos y funciones

- Qué agentes

- Qué relaciones hacia afuera

- Qué articulación interna

3. PROCESO

Más o menos participativo, pero no obligatorio para los miembros del territorio

Fuente: elaboración propia.

Frente al amplio esquema de elementos que, según el enfoque hasta ahora expuesto, debería contemplar una estrategia territorial, los esquemas de estrategia planteados bien por la literatura de sistemas regionales de innovación o bien por la Comisión Europea son algo más restrictivos.

En las estrategias RIS impulsadas por la Comisión Europea en los años noventa, al igual que en general en la literatura sobre sistemas regionales de innovación, el énfasis se ponía en corregir las deficiencias generales observadas en "la infraestructura institucional que apoya la innovación"; y las cuestiones o puntos sobre los que debía actuarse surgían de los planes elaborados por los gobiernos regionales con la ayuda de consultores y expertos. Nos alejaría un tanto de nuestra argumentación el entrar a presentar las múltiples razones de los pobres resultados derivados de aquellos ejercicios de estrategia regional (véase al respecto Landabaso, 2012) ${ }^{4}$. Pero sí que guardan estrecha relación con nuestra argumentación dos relevantes características de aquellos procesos, que, considerándose más tarde inadecuadas y causantes en parte de aquellos insatisfactorios resultados, tratarán de ser corregidos en la nueva ola de estrategias de especialización inteligente que impulsa la Comisión Europea desde comienzos de la presente década y que se conocen con el nombre de estrategias de investigación e innovación para la es-

${ }^{4}$ Entre las cuestiones que Landabaso critica de tales intentos se encuentran la escasa de interacción entre niveles de gobierno y departamentos, el que consistieran en estrategias duplicadas y sin perspectiva externa, la falta de masas críticas, el que contuvieran solo medidas de oferta y de creación de capacidades y no de demanda, y el que respondieran a modas y temas de prestigio más que al contexto local existente. 
pecialización inteligente (RIS3, por su nombre en inglés: Research and Innovation Smart Specialisation Strategies).

La primera de las dos principales características diferenciadoras de las RIS3 es que éstas destacan la necesidad de establecer prioridades temáticas o verticales. En eso las RIS3 se diferencian de las estrategias RIS, que centraban su actividad en factores de carácter más general u horizontal (tales como, por ejemplo, el reforzamiento de la universidad y de sus relaciones con la industria). Y también se diferenciaba de los planteamientos que, para favorecer el desarrollo y la disminución de las diferencias interterritoriales, efectuaba el World Bank (2008) a finales de la primera década de este siglo. Según dicho banco y los analistas como Gil (2010 y 2011) que en torno a él se movían, las políticas debían ser neutrales desde el punto de vista territorial (spatially blind). Gil y el Banco Mundial propugnaban que lo más eficaz para impulsar el desarrollo en todos los lugares era, en primer lugar, mejorar las instituciones básicas (servicios sociales y regulaciones de los mercados), de modo que con mejoras institucionales que sean "spatially blind" se unifiquen los territorios; en segundo lugar, que se desarrollen infraestructuras que conecten e integren los territorios; y, en tercer lugar, solo en circunstancias extraordinarias, recurrir a incentivos para atraer empresas a regiones atrasadas.

La principal razón que se aducía para limitar las intervenciones a esas actuaciones de carácter más general y horizontal es que, además de corresponder estas últimas a programas más fáciles de implementar, las prioridades verticales requieren de conocimientos tecnológicos y de mercado que los gobernantes y decisores públicos no poseen; y de que con ello se corría el riesgo de caer en políticas de "picking winners", que tan malos resultados y distorsionadoras de la competencia habían resultado en el pasado. Frente a tal objeción, los impulsores de las RIS3 respondían que la elección de las prioridades debía resultar de un proceso de descubrimiento emprendedor en el que, no solo toma parte el gobierno, sino que también participan los restantes agentes: empresas, organizaciones del conocimiento y sociedad civil. Es decir, la llamada cuádruple hélice. En tal sentido, esa carencia de conocimiento de tecnologías y de mercados de los representantes gubernamentales se ve contrarrestada por el conocimiento que aportan los otros agentes.

Es más, como señala la OECD (2011a: 142), "hay riesgos asociados con un excesiva influencia privada en las estrategias o políticas regionales, que requieren un equilibrio en la combinación de actores y perspectivas públicas y privadas (...) El objetivo es impedir indebidas presiones o incluso la captura de estrategias o instrumentos de financiación particulares". ${ }^{5}$ Según Breznitz (2007), en algunos casos el sector

${ }^{5}$ En el caso de las empresas, el trabajo citado de la OECD señala que el riesgo es particularmente elevado cuando una empresa o una especialización sectorial es dominante en la economía regional; y sobre las universidades que tienen una influencia dominante en la estrategia e inversiones públicas, señala que puede llevar éstas lejos de las necesidades del sector privado. Pero asimismo señala la mayor consciencia del sector privado de las tendencias globales y de las condiciones de mercado; y de la universidad y de los 


\section{Mikel Navarro Arancegui}

privado carece de las habilidades y capacidades, o de la disposición, para emprender tales procesos, y el Gobierno deberá asumir un papel activo en dicha identificación y puesta en marcha; sin embargo, a medida que el proceso avanza, el Gobierno debe ir asumiendo un papel más de facilitar y organizar (que de ordenar y controlar), y de motivar a los otros actores a que se impliquen y asuman el liderazgo del proyecto.

En suma, se pasa de un paradigma de políticas de desarrollo en el que se consideraba que los territorios debían especializarse en aquellas actividades en que disponían de ventajas comparativas, a otro en que se los territorios se especializan de acuerdo con sus ventajas competitivas. En el antiguo paradigma las ventajas comparativas de alguna manera les venían dadas a los territorios, por su dotación relativa de factores; mientras que en el nuevo las ventajas competitivas hasta cierto se construyen, aprovechando las potencialidades existentes. La dotación de factores de la cual derivan las ventajas comparativas es fruto de toda una evolución previa, que determina por donde debe ir su futuro desarrollo (past dependency); en cambio, en la construcción de las ventajas competitivas, aunque también debe tomarse en cuenta la trayectoria anterior (path dependency), tal trayectoria se ve más como un factor que influye o condiciona lo que se pueda hacer en el futuro, y no como un determinante ante el cual no cabe reacción. Por último, mientras que de acuerdo con el paradigma antiguo los gobiernos de todos los territorios debían limitarse a aplicar políticas generales de similar orientación (spatially blind), en el nuevo paradigma de políticas de desarrollo las políticas deben adaptarse al contexto particular del territorio (place based), y esa adaptación no se limita solo al ámbito de las políticas horizontales sino que alcanza también a las verticales.

\section{Figura 3. Cambio de paradigma en las políticas de desarrollo}

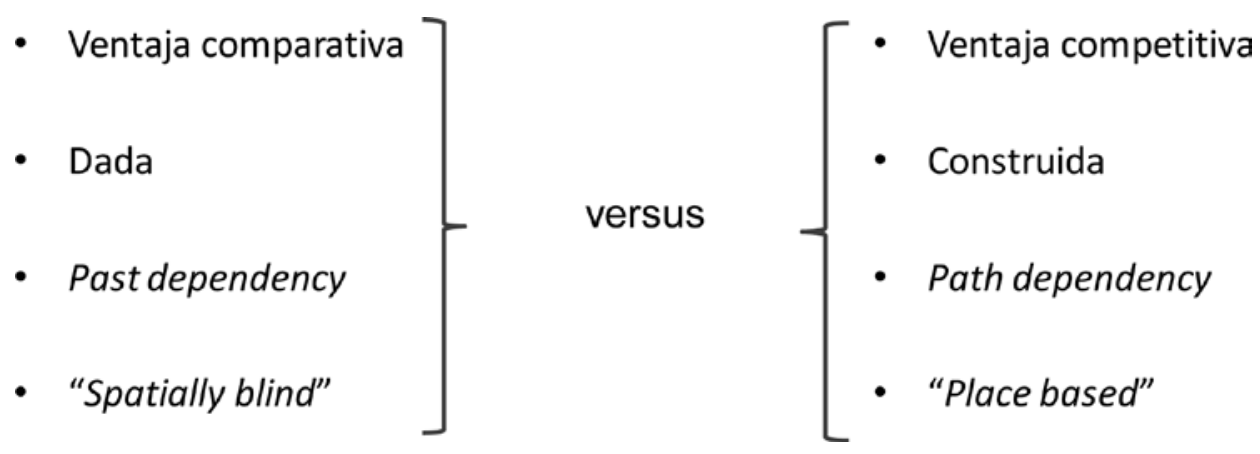

Fuente: elaboración propia.

centros de investigación, sobre las áreas prometedores para avances en la investigación básica. Por otro lado, tal como antes se ha señalado, para que la captura de rentas por las élites locales no se dé a través de su control del Gobierno regional, Barca (2011) plantea, como principio distintivo de las "place based" estrategias y políticas una gobernanza multinivel, de modo que el factor exógeno imposibilite tales conductas. 


\subsection{Las estrategias territoriales como agendas de transformación}

Como ya se ha indicado, las RIS3 comportan una lógica de intervención más vertical y no neutral. Persiguen identificar y seleccionar áreas deseables de intervención (tecnologías, campos o sub-sistemas) que puedan ser favorecidas por las políticas (Foray, 2013). No se trata de afectar solo al ritmo, sino también a la dirección de la innovación (Foray, 2009). En tal sentido se entiende que "las estrategias nacionales/regionales de investigación e innovación para la especialización inteligente (RIS3) son agendas de transformación económica integradas y contextuales" (Foray y otros, 2012: 8). El desarrollo no se concibe como una mera cuestión cuantitativa (cuánto se crece), sino también cualitativa (cambio en la composición productiva) (Neffke y otros, 2011).

Aunque del término "estrategia de especialización" pudiera a primera vista colegirse que la estrategia territorial debería buscar concentrarse y profundizar en las mismas actividades en las que hasta entonces el territorio ha destacado o podría destacar internacionalmente, en realidad eso responde a una mala elección del término con el que se denomina a este tipo de estrategias. Los autores que acuñaron este término lo que querían expresar, con el vocablo "especialización", era que las inversiones en $\mathrm{I}+\mathrm{D}+\mathrm{i}$ debían concentrarse en ciertas actividades, para así explotar economías de escala y alcanzar los umbrales críticos que operan en el ámbito de la innovación. Pero que en ningún modo pensaban que, con esas concentraciones de inversiones, se persiguiera evitar la diversificación productiva.

Todo lo contrario. Como advertía la Comisión Europea [COM(2010) 553 final], las regiones deben perseguir una cartera de actividades relacionadas, encontrando un equilibrio entre especializarse lo suficiente para ser competitivas, pero no demasiado como para dificultar la diversificación y exponer la región a los riesgos de cambios en las condiciones de los mercados o en otros hechos externos impredecibles. Según McCann y Ortega-Argilés (2011), las RIS3 deben perseguir una "diversificación especializada", es decir, una diversificación basada en tecnologías relacionadas relevantes para el crecimiento. Las estrategias de especialización inteligente estarían constituidas por el conjunto de actuaciones emprendidas para avanzar hacia esa diversificación especializada. Camagni (2011) precisa algo más la terminología y prefiere hablar de una estrategia de diversificación y mejora inteligente (smart diversification and upgrading) de actividades y funciones existentes, esto es, "de una creativa y apropiada diversificación de las especializaciones existentes y de una mejora de su calidad" (pág. 59).

¿Qué vías habría para avanzar hacia esa diversificación y mejora inteligente?

La literatura de las RIS3 ha definido varias vías por las que las regiones y los territorios pueden diversificar su estructura productiva (COM(2010) 553 final; Foray 2013; Aranguren y otros, 2012b; Orkestra, 2013): 
- Modernización. La Comisión Europea define la modernización como la mejora y diversificación que tiene lugar dentro de una actividad, sector o clúster ya existente, como fruto de la mejora de los recursos humanos y tecnológicos. Hoy día se plantea que en gran medida la modernización provendrá del desarrollo de aplicaciones de Tecnologías de Utilidad General (conocidas como GPTs, por General Purpose Technologies) o Tecnologías Facilitadoras Esenciales (KETs, por Key Enabling Technologies) en actividades o campos determinados, a semejanza de lo que sucedió, por ejemplo, en las décadas de los 70, 80 y 90, cuando la microelectrónica empezó a aplicarse en la máquina herramienta.

- Expansión (o extending). Se trataría de la penetración en nuevos mercados o ámbitos de actividad, aprovechando las similitudes de bases de conocimiento científico-técnico entre la actividad de origen y la nueva actividad. O dicho de modo más técnico, el descubrimiento de nuevos nichos mediante la explotación de economías de alcance. Ejemplos de ello serían la aplicación de los conocimientos generados en la aeronáutica para el desarrollo de la industria de los GPS y los satélites, o la expansión al sector de energía eólica off-shore desde la eólica on-shore.

- La emergencia o fundación radical. Consiste en la aparición en la región de una actividad totalmente nueva. Por ejemplo, la aparición en el territorio de empresas bio-tecnológicas.

- La combinación (cross-sectoral). Se denominaría así a la aparición de nuevas actividades como resultado de la combinación de bases de conocimiento diferentes. Las TIC, en particular, han aumentado enormemente las posibilidades de combinación de productos hasta entonces diferentes y la aparición de nuevos modelos de negocios. Como señalan Porter y Heppelmann (2014) hoy día muchas de las fronteras o límites sectoriales se desvanecen y surgen otras nuevas, al pasar las empresas de ofertar productos a ofertar soluciones, sistemas de productos o, incluso, sistemas de sistemas, tales como pudieran ser un edificio inteligente.

\section{ESTRATEGIAS DE TRANSFORMACIÓN PRODUCTIVA EN EL PAÍS VASCO}

El País Vasco es considerado por la literatura como un ejemplo de transformación productiva exitoso, éxito que en buena parte se atribuye a las acertadas estrategias de desarrollo impulsadas por su gobierno regional desde comienzos de los 80 , momento en que tiene lugar un notable proceso de recuperación de competencias por aquél (Orkestra, 2008; OECD, 2011b; Morgan, 2013). Aunque en aquellos tiempos no se había acuñado el término de estrategia de especialización inteligente, las características que presentan los diversos planes y políticas puestos en marcha en el País Vasco desde comienzos de los años 80 coinciden en buena medida con lo que posteriormente la literatura RIS3 propugna o recomienda para estas (Navarro, 2011). 
No cabe, en el corto espacio de este artículo, exponer todos los componentes contenidos en la Figura 2 antes comentados, relativos al objetivo, contenido y procesos de las estrategias aplicadas en el País Vasco desde comienzos de los años 80 hasta nuestros días. En su lugar, por la mayor atención que se les ha prestado en la literatura RIS3, el artículo se limitará a ligar la transformación productiva que en él tiene lugar con las prioridades temáticas o verticales que en él se impulsan, y a mostrar cómo son los rasgos de las diferentes gobernanzas detrás de aquellas. El análisis se concretará más para el período más reciente, en que en respuesta a los requerimientos de la Comisión Europea se ha planteado una nueva RIS3 para el País Vasco. Esta intenta abordar tanto la profundización en la diversificación especializada y mejora que viene del pasado como afrontar los retos que con las anteriores estrategias habían quedado sin resolver. En particular, se intentará ver cómo las vías de transformación (modernización, expansión, fundación radical y combinación) hacia la diversificación productiva presentan una diferente materialización de unas prioridades temáticas a otras.

\subsection{Fases atravesadas por la estrategia territorial en el País Vasco}

En la evolución de la economía vasca desde 1980, año de creación del primer Gobierno Vasco tras la aprobación del Estatuto de Autonomía, hasta nuestros días, cabe distinguir tres grandes períodos: 1980-1990, 1991-1998 y de 1999-hasta la actualidad (véase Navarro y otros, 2011; Aranguren y otros, 2012).

En el primer período, 1980-1990, fase en la que el nuevo Gobierno, además de tener que construir el entramado administrativo regional, debe afrontar la grave crisis que desde la segunda mitad de los 70 sacude a la economía vasca y la entrada en la Comunidad Europea en 1986, lo que resulta más característico es la decidida apuesta que efectúa el Gobierno Vasco por el mantenimiento de sus sectores industriales tradicionales, muy nucleados en torno al metal: siderurgia, construcción naval, forja, fundición, máquina-herramienta, automoción y material ferroviario, fundamentalmente. Cuando desde la literatura se propugnaba una política industrial neutral desde el punto de vista sectorial, el Gobierno Vasco, tanto a través de su destacada participación en los planes de reconversión establecidos por el Gobierno Central como por el establecimiento de programas propios de apoyo a empresas y sectores industriales compuestos fundamentalmente por pymes, impulsó una decidida política de reestructuración que permitió la renovación y el retorno a la viabilidad de buena parte del tejido industrial vasco. Fue una política que, en la terminología anteriormente expuesta de vías de transformación productiva, cabría denominar de "modernización", que radicó, no tanto en mejoras de productividad obtenidas merced a la aplicación de actividades de I+D (bien en estricto sentido o bien a través de tecnologías de uso genérico), sino en actividades de innovación más tradicional (inversiones en maquinaria y mejoras organizativas, fundamentalmente). 
El gran protagonismo ejercido por el Gobierno Vasco en ese período fue mucho más allá del papel de mero facilitador o catalizador que se propugna en la literatura de la RIS3. Ese protagonismo era hasta cierto punto obligado, pues la clase empresarial era incapaz de asumirlo: en parte, porque a los factores propios de la crisis económica mundial (que podían resultar más acentuados en el caso vasco por su especialización en los sectores más afectados por la crisis), vino a sumarse un cambio del marco económico en que hasta entonces había jugado (el paso de una economía relativa cerrada y protegida, heredada del franquismo, a una economía abierta e integrada en la Comunidad Europea desde mediados de los 80) y la actuación de ETA (quién llevó a cabo una clara política en contra del empresariado: secuestros, "impuesto revolucionario" y demás presiones y extorsiones) (Orkestra, 2008). Por último, respecto al proceso, las políticas de reestructuración industrial establecidas por la Administración central se negociaron con los sindicatos, y las políticas de reestructuración del Gobierno vasco solían consultarse a empresarios y sindicatos, aunque las políticas de reestructuración sectoriales del Gobierno vasco no fueron formalmente aceptadas por estos últimos. Este tipo de actores (asociaciones empresariales de carácter general y sindicatos) perderá protagonismo en las subsiguientes fases, como interlocutores o participantes en el diseño de las políticas.

El período 1991-98 es un período de transición, en el que las políticas no son tan reactivas como en el período anterior, sino que enmarcándolas existe un plan formal de estrategia industrial, fruto claro de un proceso top-down. En lo que respecta a las políticas de "diversificación inteligente y mejora", el hecho más destacado es la puesta en marcha de una pionera y decidida política de clusterización. La mayor parte de la misma se orienta a sectores y actividades tradicionales de la economía vasca, que, aunque incluye la definición de proyectos estratégicos de I + D por las asociaciones clústeres creadas al respecto, en lo fundamental la actividad de las asociaciones se centró en el impulso a la cooperación y en actuaciones en ámbitos como la mejora de la calidad y la internacionalización. Tal política de clusterización cabría considerarla como una modalidad de "modernización", pero más avanzada que la mera política sectorial del período anterior. En todos estos casos si bien la primera llamada para la puesta en marcha de la política provino de la Administración, los clústeres así identificados no se activaron si las empresas no estaban dispuestas a participar en ellos. $\mathrm{O}$ incluso, hubo actividades inicialmente no planeadas en las que, por solicitud de las asociaciones sectoriales en ellas existentes, finalmente se constituyó una asociación clúster. En todo caso, la Administración siguió manteniendo un protagonismo grande en las asociaciones clústeres.

Pero junto al impulso de la clusterización en sectores tradicionales, el Gobierno Vasco inició una labor de impulso a proyectos de diversificación industrial que cabría incluir, entre las vías de transformación productiva, bajo la categoría de "expansión" (extending). Entre ellos destaca el decidido apoyo dado por el Gobierno vasco a tres grandes empresas vascas (ITP, Sener y Gamesa) que, habían 
tenido diversos contactos con la industria aeronáutica, para que desarrollaran un proyecto de penetración en el sector aeronáutico, al que luego se sumaron más de una decena de pequeñas empresas. Todo ello dio lugar a la aparición de una nueva y creciente actividad en la región: la aeronáutica, y a la creación de una asociación clúster para su apoyo. En suma, la entrada en un nicho de actividad o sector distinto del originario de las empresas, mediante la explotación de economías de alcance. Aparte de esa diversificación hacia la aeronáutica, aprovechando la coyuntura política y las inversiones en infraestructura de fibra óptica realizadas por el gobierno regional, se impulsó la creación de Euskaltel y el desarrollo del sector de telecomunicaciones, que desde la perspectiva del territorio vasco suponía la "emergencia" de actividad empresarial propia en ese ámbito.

Es más, la estrategia de diversificación del Gobierno vasco fue más allá del sector industrial y abordó también un proceso de regeneración de las ciudades, especialmente de Bilbao. Una señal destacada de dicha política fue el proyecto del Guggenheim, que trataba de situar a la ciudad en una red mundial de centros culturales y recreativos. Aunque siempre cabría ver dicha estrategia como una "modernización" de una serie de actividades ligadas a las industrias creativas, la transformación experimentada por Bilbao abarca tantos aspectos y ha sido tan profunda que también podría verse como una "expansión". En todo caso, fue una estrategia cuyo modo de innovación principal no radicaba en I+D.

Por último, el período que va desde 1999 hasta la actualidad es un período en el que continúa la existencia de planes o estrategias formales de competitividad de carácter bastante comprensivo, para cuyo diseño se establece ahora un proceso participativo, que solo en el presente PCTI-2020 alcanza también a su implementación (y previsiblemente seguimiento). Es una estrategia que perseguía llevar a cabo la transición de la economía vasca de un estadio competitivo basado en la eficiencia a otro basado en la innovación. En lo que hace referencia a las medidas de carácter vertical ligadas a una especialización inteligente, cabría distinguir:

- Por un lado, una reestructuración y ampliación del número de actividades sujetas a iniciativas clúster, así como diversas medidas que pretenden mejorar su funcionamiento y dotarles una orientación más estratégica (cosas todas ellas, que cabría catalogar como "modernización" por medio de clústeres).

- Por otro lado, el inicio de una explícita política de diversificación y mejora estratégica basada en la I+D, por los planes de ciencia tecnología e innovación que se aprueban en el nuevo milenio. A su vez, dentro de la diversificación y mejora basada en I+D cabría distinguir, siguiendo la terminología empleada en el PCTI-2010, las actuaciones tendentes a "apoyar el presente" (esto es, sectores y actividades en los que ya el País Vasco era relativamente fuerte, como puede ser la manufactura o fabricación avanzada) de las destinadas a "construir el futuro" (es decir, sectores o actividades sin apenas 
presencia en el País Vasco, pero que se consideraba que iban a ser clave en el porvenir, como las biociencias y las nanotecnologías).

En general cabría sostener que en el período de bonanza en que había abundancia de recursos y la industria vasca existente se desenvolvía bien en los mercados, el énfasis de la política y una notable cantidad de recursos públicos se concentró en poner las bases para la creación de ese futuro. Muestra de ello es que las únicas estrategias específicas que aprueba el Gobierno Vasco y las únicas áreas en que se crean Centros de Investigación Cooperativa (CIC) de naturaleza física (es decir, con un número importante de investigadores y notables equipamientos e infraestructuras científicas propios) corresponden a apuestas de futuro: las estrategias Biobasque y Nanobasque, y los centros Biogune, Biomagune y Nanogune.

Sin embargo, cuando llega la crisis se aprecia un cambio de orientación en el ámbito en que se centran las iniciativas y la atención del Gobierno Vasco. Aunque sin abandonar la apuesta por esas actividades emergentes y de carácter un tanto rupturista (en las que se había realizado ya una gran apuesta de generación de capacidades, que se piensa que se perdería de otro modo), resulta claro que la atención del Gobierno Vasco va reorientándose hacia iniciativas más ligadas a capacidades económico-empresariales ya existentes: inicialmente hacia la energía y luego hacia la fabricación avanzada. Así, el último CIC físico que se crea es Energigune (2007) y en 2010, por primera vez, se aprueba una estrategia de desarrollo tecnológicoempresarial en el ámbito de la energía, denominada Energibasque. Entre las cadenas de valor energéticas del País Vasco se encuentran tanto actividades tradicionales (por ejemplo, refino de petróleo) como emergentes (eólica off-shore o undimotriz); y en algunas de ellas las empresas vascas ocupan puestos de liderazgo en el contexto internacional. En cuanto a la fabricación avanzada, hubo un intento postrero del Gobierno Vasco presidido por el Patxi López, a finales de 2012, de aprobar una estrategia específica en esta área, pero no es hasta finales de 2014, tras la inclusión de la fabricación avanzada como una de las tres prioridades temáticas de la RIS3 vasca, que el Departamento de Desarrollo Económico y Competitividad del Gobierno Vasco elabora y presenta la que denomina Estrategia de Fabricación Avanzada 2020.

En suma, dependiendo del estadio de desarrollo en que se encuentra la región, las estrategias de especialización inteligente varían y no descansan necesaria o principalmente en la I+D. Desde comienzos de los años 80 a la actualidad en el País Vasco se aplican diferentes modalidades de RIS3, pero salvo en la última etapa ellas no descansan mayoritariamente en la I+D. Es por ello, que resulta más conveniente abordar una aproximación amplia del concepto de RIS3, de forma que se integren en la misma estrategia de las regiones que se encuentran en estadios de desarrollo menos avanzados.

Tanto por no alargar excesivamente la presentación de la evolución que va mostrando la estrategia de especialización inteligente del País Vasco a lo largo 
de este siglo como porque es la aprobada a comienzos de 2015 la que se ha realizado ajustándose más estrechamente a los principios de las RIS3 propuestos por la literatura y la Comisión Europea, será en esta última en la que se centrará el siguiente apartado, indicando cómo se han elegido las prioridades temáticas y valorando la elección efectuada, mostrando como dentro de cada prioridad hay diferentes cadenas de valor o segmentos en las que generalmente operan diferentes vías de transformación productiva y exponiendo el diferente modo de implicación del gobierno y de los distintos agentes en sus procesos de descubrimiento emprendedor.

\subsection{La estrategia de transformación productiva actual del País Vasco}

\subsubsection{Prioridades temáticas estratégicas de la RIS3}

Son tres los criterios en que se ha basado la selección de las prioridades temáticas en la RIS3 del País Vasco. En primer lugar, en la existencia de capacidades empresariales generadoras de empleo y riqueza y con capacidad para traccionar y explotar las innovación. En segundo lugar, en la presencia de capacidades científico tecnológicas significativas ligadas a esas áreas. Y, en tercer lugar, en la capacidad de aplicación de las dos anteriores a ámbitos de oportunidad de gran potencial de crecimiento. (Véase Figura 4).

\section{Figura 4. Prioridades temáticas y nichos de oportunidad de la RIS3 del País Vasco}

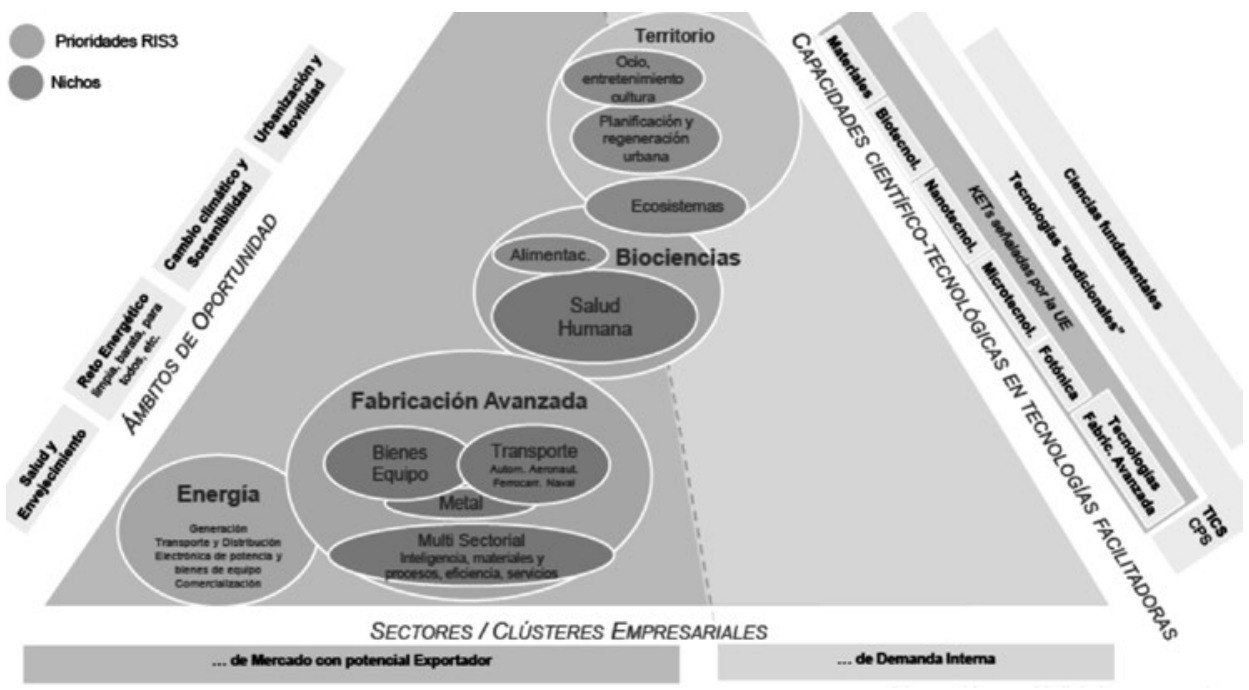

Fuente: Gobierno Vasco (2014), p. 15. 
Para cada uno de los tres tipos de criterios se manejaron una serie de indicadores que permitían medir esas capacidades. Así, por ejemplo, con relación a las capacidades empresariales, se analizó el peso y grado de especialización de la economía vasca en tales sectores, las cuotas que tenían en las exportaciones mundiales, etc. Para las capacidades científico-tecnológicas se atendió al número de investigadores existentes en cada ámbito, a la cantidad y calidad de sus outputs (por ejemplo, a publicaciones y retornos de programas comunitarios), a la aplicabilidad y probabilidad de explotación económica de sus resultados. Y, sobre los ámbitos de oportunidad, al grado en que cada uno de los grandes retos sociales impactaba de modo diferencial en el País Vasco. De esa manera se llegó a la selección de tres grandes prioridades temáticas (las biociencias-salud, la energía y la fabricación avanzada) y de una serie de oportunidades o nichos de mercado ligados, en los que el mercado se consideraba que era principalmente de demanda interna.

En el reciente informe de competitividad publicado por Orkestra (2015) se ha intentado caracterizar las tres prioridades temáticas, de acuerdo con diversos aspectos considerados clave por la literatura RIS3 y con el tipo de apuestas en ellas efectuado.

Biociencias-salud (que por abreviar se denominará solo Biociencias en lo sucesivo) es un tipo de apuesta rupturista y a largo plazo. Hoy en día el País Vasco no tiene en ese ámbito grandes capacidades económico-empresariales (su peso en el PIB vasco es inferior al 1\%) y en la mayoría de las bioempresas vascas no se ha alcanzado el nivel de competitividad; pero las expectativas de crecimiento a medio plazo son grandes. Gracias al esfuerzo de inversión llevado a cabo en la última década en el ámbito bio-sanitario se ha logrado crear importantes capacidades científico-tecnológicas, muy diferentes de las dominantes en el País Vasco (típicamente ingenieriles), aunque combinables con ellas. En esta apuesta, el mayor impacto económico no se espera que venga de la creación de empresas bio-tecnológicas (que siempre supondrán un bajo porcentaje del empleo vasco total), sino de la orientación de los sectores tradicionales hacia el mundo bio-sanitario, bien como proveedores (por ejemplo, la máquina herramienta vasca) bien como usuarios (por ejemplo, la industria alimentaria). Se trataría de una actividad emergente en el mundo, con cierto retraso en el País Vasco.

La apuesta por la energía es una mezcla de incremental y disruptiva, con impacto tanto a corto como a largo, en actividades con expectativas de crecimiento grande que suponían ya el $5 \%$ del PIB vasco, y con empresas vascas altamente competitivas y algunas de ellas líderes mundiales. Dentro del clúster de energía vasco existen cadenas de valor muy distintas, algunas relativamente tradicionales en las que las empresas vascas están bien posicionadas (redes eléctricas, petróleo y gas, eólica y solar termoeléctrica), junto a otras tecnológicamente emergentes y con volumen de negocio relativamente pequeño (eficiencia energética, biomasa y biocombustibles) y otras que a día de hoy todavía no son explotables comercialmente pero con grandes perspectivas de futuro (almacenamiento, energía mari- 
na, gas natural vehicular y coche eléctrico). La apuesta energética combina, por lo tanto, áreas desarrolladas, con otras emergentes y otras embrionarias.

Por último, la fabricación avanzada es la principal actividad por la que es conocido el País Vasco en el exterior. Está compuesto por un conjunto de actividades que, suponiendo más del $20 \%$ del PIB vasco y tres cuartas partes de sus exportaciones, se caracterizan por un tipo de innovación más incremental y con expectativas de crecimiento medio. Dentro de esta prioridad hay sectores proveedores de productos de primera transformación (p.e. siderurgia), medios de producción (p.e. máquina herramienta), servicios avanzados (p.e. TIC e ingenierías) y sectores usuarios finales (aeronáutico, automoción, ferrocarril, naval y energía, fundamentalmente). Se trataría, por lo tanto, de actividades un tanto maduras, pero con posibilidades de transformación y modernización.

\section{Figura 5. Capacidades científico-tecnológicas y empresariales en las prioridades temáticas de la RIS3 del País Vasco}

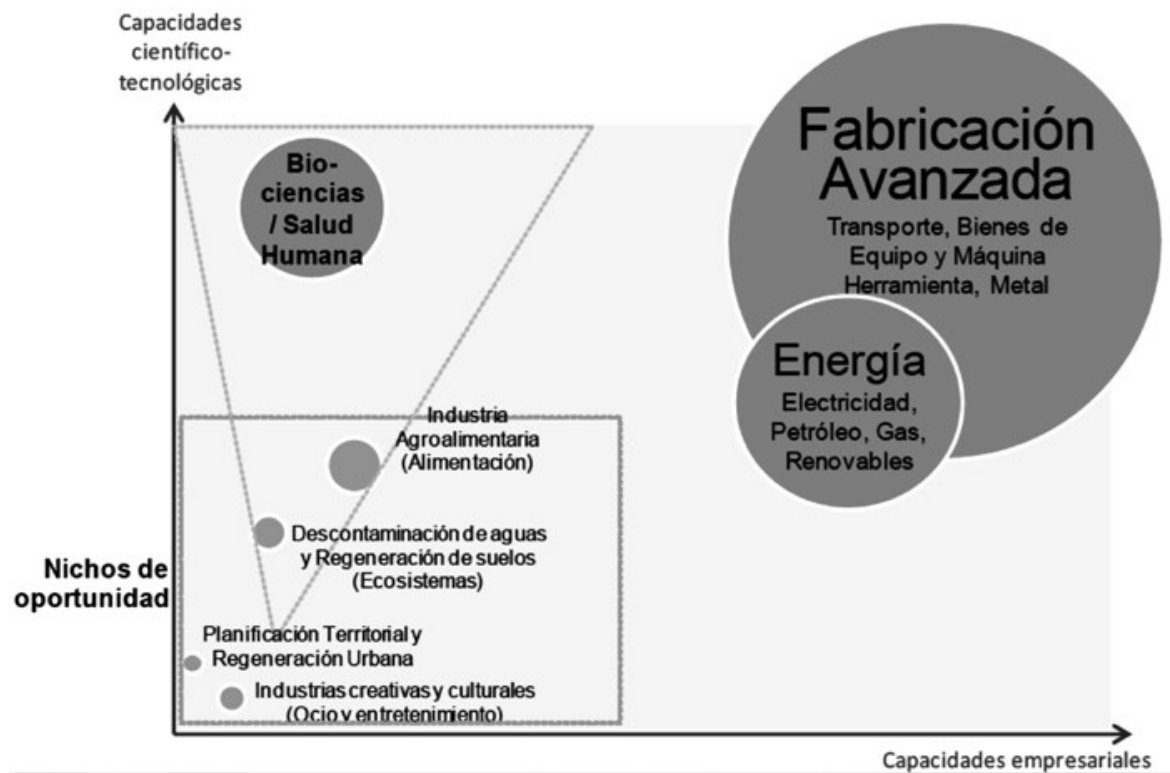

Fuente: Gobierno Vasco (2015), p. 44.

\subsubsection{Vías de transformación productiva en cada prioridad}

El papel jugado por las cuatro posibles vías de transformación productiva antes (a saber: modernización, expansión, fundación radical y combinación) en las tres prioridades temáticas estratégicas seleccionadas por la RIS3 del País Vasco es claramente diferente. 
En el ámbito de las biociencias, la fundación radical ha sido hasta ahora la vía de diversificación predominante, con la creación de más de medio centenar de empresas biotecnológicas en el País Vasco, región en la que, a diferencia de lo sucedido en bastantes biorregiones, la industria farmacéutica era una actividad bastante marginal hasta la puesta en marcha de esta estrategia. Dentro de la vía denominada "expansión" cabe incluir los casos de algunas empresas tradicionales (por ejemplo, Cikautxto; véase Orkestra, 2013) que se han convertido en proveedores de las empresas biotecnológicas o del mundo sanitario. La "modernización" en esta prioridad iría ligada a la incorporación de biocomponentes a los productos y procesos de empresas vascas en sectores tradicionales, pero hasta ahora el recurso a esta vía ha sido escaso en la CAPV, aunque el potencial al respecto es grande. Por último, si bien bastantes de los nuevos productos de las empresas biotecnológicas resultan de una "combinación" o convergencia de diferentes tecnologías (TICs, bios, nanos y demás tecnologías facilitadoras esenciales), más allá de eso no se conocen casos de empresas biotecnológicas vascas que hayan combinado sus capacidades con las de otras empresas para ofertar productos nuevos.

En la prioridad energética, la vía de diversificación y mejora predominante en los últimos años ha sido la "expansión", de la mano de la aparición de nuevas fuentes de energía como el gas natural (y, más recientemente, el gas no convencional) y las energías renovables (eólica, solar y biomasa). Así, por ejemplo, empresas energéticas vascas que se movían en el campo de la eólica on-shore, junto con otras que operaban en el ámbito de la construcción naval, han iniciado un proceso de diversificación hacia la eólica off-shore. La estrategia de "modernización" ha sido otra constante en las empresas del sector, por ejemplo a través de la aplicación de la microelectrónica y las llamadas tecnologías facilitadoras (KET) en el área de sensores, memorias y conectividad para todos los productos y soluciones relacionados con la generación, conexión a la red y transporte y distribución de energía. Existen también ejemplos de diversificación por combinación de capacidades y recursos de varios sectores (crosssectoral), aunque en estadios muy preliminares, tales como el vehículo eléctrico y el gas natural vehicular. También existen opciones para la aparición de nuevos sectores o subsectores (emergencia o fundación radical), como resultado de proyectos en curso en áreas de generación híbrida y almacenamiento, o en energía de las olas.

Finalmente, en la fabricación avanzada la vía principal de diversificación y mejora pasa por la modernización, principalmente por la incorporación de las TIC e internet a la producción, tal como se propugna desde el paradigma de Industria 4.0. Son numerosos también los casos de "expansión" en la economía vasca, por salto de empresas entre los diferentes clústeres integrantes de esta estrategia (por ejemplo, por el paso de empresas de automoción hacia la aeronáutica). Y son muy grandes las posibilidades que ofrece la servitización, aunque hasta ahora no muy explotadas por las empresas vascas. La servitización y el paso de ofrecer un producto simple a ofrecer soluciones conjuntas en algunos casos cabría calificarla como "modernización" (por ejemplo, cuando es fruto de la mera incor- 
poración de TICs) y en otros como "combinación" (cuando la solución conjunta es compleja y combina múltiples productos y servicios diferentes).

\subsubsection{Procesos de adopción e implementación del plan y las prioridades temáticas}

Hagamos, referencia, por último a las características del proceso ligado a la determinación de las prioridades temáticas y, en particular, al papel jugado en ello por el Gobierno Vasco.

La idea de las tres grandes prioridades temáticas partió del Informe de Competitividad de 2013 realizado por Orkestra, el Instituto Vasco de Competitividad, entidad nacida al amparo de la Universidad de Deusto, como fruto de una colaboración público-privada entre los mundos de la administración, de la empresa y de la universidad. Orkestra en tales años estaba inmersa en el desarrollo de un marco analítico de las estrategias territoriales y desde el primer momento había tomado parte en los desarrollos de la RIS3 impulsados desde Bruselas, lo que le había permitido, además de conocer de primera mano los principios que informaban el nuevo tipo de estrategias, desempeñar un papel destacado en la incorporación de aquellos al País Vasco. A partir de tal conocimiento y de los análisis críticos que estaba llevando a cabo sobre las anteriores estrategias territoriales, las prioridades en ellas contenidas y, en general, sobre la competitividad y el sistema de innovación del País Vasco, concluyó que las tres prioridades citadas conformaban una apuesta que combinaba bastante equilibradamente apoyos al presente y construcciones del futuro, procesos de diversificación incrementales y rupturistas, bases de conocimiento analíticas y sintéticas, y que sin renunciar a seguir generando nuevas capacidades ponía el énfasis en la explotación económica de las ya generadas. Tal idea, antes de ser hecha pública en su informe de competitividad, había sido sometida a contraste con relevantes personas, pertenecientes tanto al mundo de la administración, como de las empresas y de las organizaciones del conocimiento (universidad, centros de investigación cooperativa y centros tecnológicos).

La idea fue asumida por el Departamento de Desarrollo Económico y Competitividad (DDEC), con quién Orkestra empezó a trabajar en torno a la RIS3 vasca, y fue presentada también a los otros departamentos del Gobierno Vasco más directamente implicados con la I+D+i. Con objeto de evitar posibles cuestionamientos de las tres prioridades, el DDEC llevó a cabo, con la ayuda de SPRI, Innobasque y una consultora, una justificación más detallada de las capacidades económico-empresariales, científico-tecnológicas y de oportunidades de mercado existentes en esas tres prioridades. Apoyándose en tales estudios, las tres prioridades se debatieron de nuevo con los restantes departamentos, con otras instituciones (p.e. diputaciones forales) y con algunos de los principales agentes de la red vasca de ciencia tecnología e innovación (universidad y centros tecnológicos, especialmente). En dichos contactos y a solicitud de esos otros agentes, se decidió añadir a las tres prioridades verticales, que se calificaban de "estratégicas", una serie de nichos de oportunidad. 
Finalmente, el Gobierno Vasco decidió elaborar un nuevo Plan de Ciencia, Tecnología e Innovación, liderado por Lehendakaritza (Presidencia), que incluyó las tres prioridades verticales estratégicas y los nichos de oportunidad contenidos en el documento del DDEC. Y tanto el documento sobre prioridades (que se denominó "RIS3 Euskadi, Prioridades Estratégicas de Especialización Inteligente de Euskadi") como el Plan de Ciencia, Tecnología e Innovación (que se denominó "PCTI Euskadi 2020. Una estrategia de especialización inteligente") fueron debatidos y aprobados por los órganos de gobernanza contemplados por el nuevo plan: fundamentalmente el Consejo Vasco de Ciencia, Tecnología e Innovación (CVCTI) (Véase Figura 6). Aunque, como fruto de los cambios introducidos en 2014 en su composición, representantes empresariales y de los centros tecnológicos habían pasado a estar presentes en el CVTI (junto a la representación del Gobierno Vasco, de las Diputaciones forales y de las universidades, ya de antes miembros del mismo), y si bien en los contactos informales previos y en la sesión formal de discusión en el CVTI del documento RIS3 Euskadi y PCTI-Euskadi 2020 se introdujo alguna pequeña modificación en los planes, cabe sostener que el PCTI Euskadi 2020 y las prioridades temáticas en él contempladas fueron fundamentalmente fruto del diseño y decisión del Gobierno Vasco, que a su vez lo aprobó en su Consejo de Gobierno en enero de 2015.

\section{Figura 6. Órganos de gobierno del sistema vasco de ciencia, tecnología e innovación}

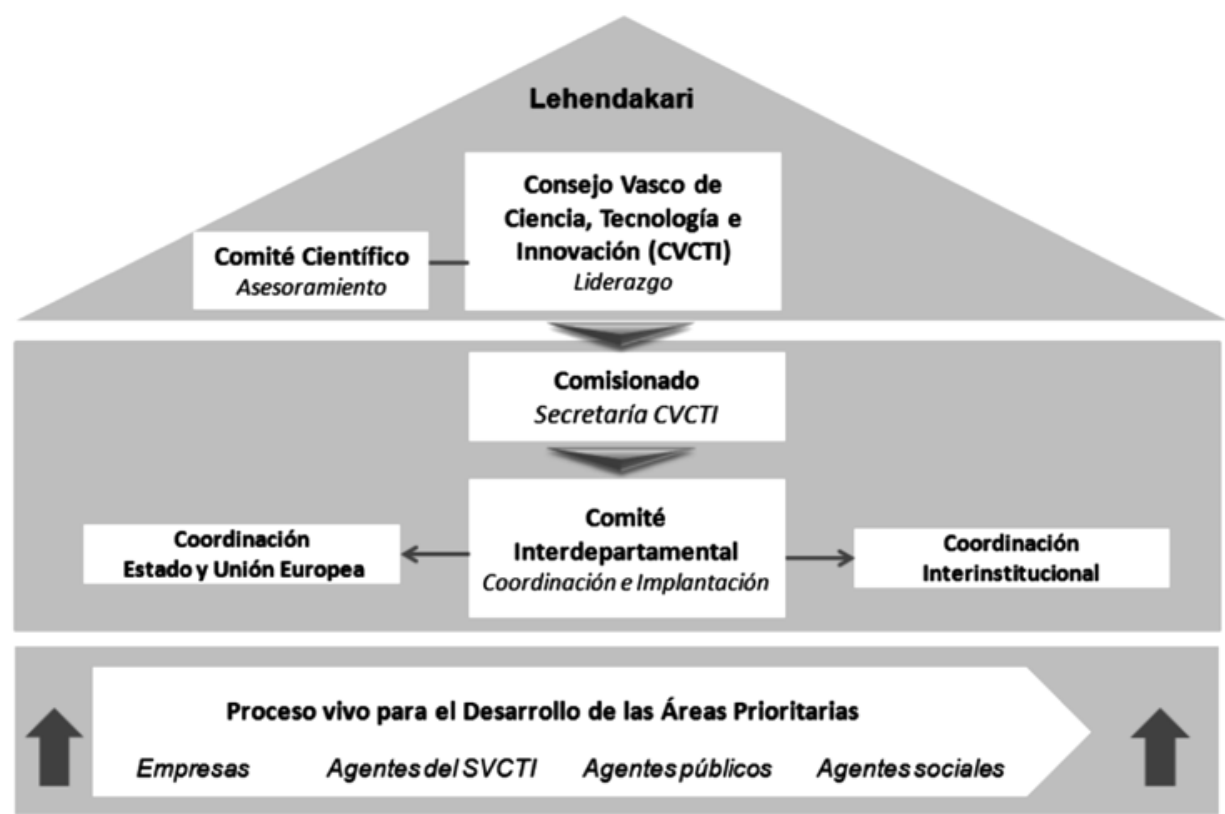

Fuente: Gobierno Vasco (2015), p. 86. 
Así pues, el diseño del conjunto del plan y de las prioridades temáticas en él recogidas es fruto, fundamentalmente, del Gobierno Vasco, quien somete sus planes a consulta y contraste con los principales agentes de la RVCTI y algunos representantes empresariales, así como con algunos expertos externos (tanto con el Comité Científico contemplado en el esquema de gobernanza como con Kevin Morgan, un experto internacional que había realizado algún informe de evaluación de la RIS3 del País Vasco para la Comisión Europea). Dentro del Gobierno Vasco, aunque inicialmente el liderazgo lo asumió por delegación el DDEC, posteriormente fue Lehendakaritza quien pilotó el proceso, aunque asumió el documento sobre las prioridades temáticas del plan elaborado por el DDEC.

En cuanto a cada una de las prioridades temáticas, para su desarrollo se han creado unos grupos de pilotaje, en los que están representados tres grupos de agentes: la Administración y diversos organismos públicos, las empresas y las asociaciones clúster, y los agentes de ciencia, tecnología e innovación. Centrándonos en las tres prioridades temáticas estratégicas, en dos de ellas (Fabricación avanzada y Energía) el liderazgo lo ha asumido el DDEC, mientras que en otra (Biociencias) el liderazgo es conjunto entre dicho departamento y el de Salud. No obstante, la supervisión y coordinación de todos los grupos de pilotaje corre a cargo de Lehendakaritza. ${ }^{6}$ Los grupos se acaban de constituir en el verano de 2015 y además de aprobar su modo de organización (p.e. la creación de un comité director, una comisión delegada, grupos de trabajo temáticos y una secretaría técnica), una serie de criterios para la selección de proyectos dentro de cada ámbito de especialización y una concreción de cada prioridad temática ${ }^{7}$, poco han podido avanzar de entonces hasta hoy, de modo que no se puede decir mucho sobre el papel asumido en ellos por cada tipo de agente y cómo tales agentes se están implicando y llevando adelante el proceso de descubrimiento emprendedor en cada una de tales áreas.

No obstante, de la experiencia habida hasta entonces en el desarrollo de las estrategias específicas (Biobasque, Energibasque y Fabricación avanzada 2020) se pueden extraer algunas conclusiones sobre el diferente tipo de participación de los agentes que se da en unas y otras. Así, en Biociencias, el nivel de intervención de la Administración fue muy grande, tanto por la necesidad de "provocar" la aparición

\footnotetext{
${ }^{6}$ Hasta el PCTI-2015, el liderazgo y elaboración de los planes de ciencia, tecnología e innovación (que constituían de facto las RIS3 del País Vasco) lo tuvo el Departamento de Industria (hoy denominado de Desarrollo Económico y Competitividad). En el PCTI-2015 el diseño del plan lo condujo Lehendakaritza, pero el diseño e implementación de las estrategias específicas correspondía a los Departamentos concretos, sin que se contemplara una coordinación general desde Lehendakaritza. En el PCTI-2020 se ha dado un paso adelante, y Lehendakaritza se ocupa de la coordinación general, de modo que tanto el diseño como la implementación son más transversales dentro del Gobierno.

${ }^{7}$ Por ejemplo, en Fabricación avanzada las prioridades son Fabricación aditiva, Robótica avanzada, Sistemas ciber-físicos, Realidad aumentada, Cloud Computing, Big Data, Nuevos Materiales, y Máquinas y sistemas flexibles e inteligentes.
} 
del clúster (ya que no existía tejido de empresas biotecnológicas previo) y por la complejidad de las formas de intervención requeridas (promoción, financiación, regulación, validación, acreditación, prescripción y compra). En Energía se da un gran nivel de intervención en el ámbito energético general (al ser un input clave y estratégico) y mediante múltiples formas (entre las que destacan la regulación y desarrollo de infraestructuras); pero la intervención es menor en el desarrollo tecnológico-empresarial, entre otras cosas, por la gran capacidad y tamaño de las empresas del sector. Y en fabricación avanzada ha habido un alto nivel de apoyo a tal tipo de actividades, pero sin una estrategia explícita hasta fechas recientes, en parte por la fortaleza que las propias empresas presentaban y, en parte, por ser un sector maduro y con menos fallos de mercado y no propio de políticas "mission oriented".

A su vez, centrándonos en el diferente rol de los agentes no gubernamentales, en Biociencias, aunque las empresas biotecnológicas tienen capacidades de $\mathrm{I}+\mathrm{D}$, proporcionalmente las de las infraestructuras de I+D son mucho mayores (ya que han sido las principales destinatarias de las ayudas públicas), y eran fundamentalmente los Centros de Investigación Cooperativa (Biogune y Biomagune) los que más influían en la marcha de la estrategia de biociencias, ante la debilidad empresarial. En Energía, en cambio, las empresas poseían amplias capacidades de económicas y de $\mathrm{I}+\mathrm{D}$, de modo que generaban la mayor parte de la $\mathrm{I}+\mathrm{D}$ que requerían y eran las que dominaban la relación con las infraestructuras de I+D. Y en Fabricación avanzada se daba una situación más pareja de capacidades entre empresas e infraestructuras de $\mathrm{I}+\mathrm{D}$, así como una mayor interacción y colaboración entre estos dos tipos de agentes.

Señalemos, finalmente, sobre los procesos de descubrimiento emprendedor que deberán impulsarse en los grupos de pilotaje constituidos para el desarrollo de las prioridades temáticas, que a la vista de la experiencia habida hasta ahora en los tres ámbitos de prioridad temática estratégica del País Vasco puede concluirse que las características de tales procesos varían enormemente en plazos, tipos de conocimiento, financiación requerida, comercialización, papel e instrumentos de intervención del gobierno, dependiendo de cada cadena de valor (p.e. es muy diferente, incluso dentro de la misma prioridad de Biociencias, la de fármacos de la de biodetergentes), de la vía de transformación productiva (p.e. fundación radical o expansión), del origen del emprendimiento (p.e. empujón de la ciencia, a partir de unas start-up surgidas de la investigación en biociencias; o tirón de la demanda, como pueda ser la necesidad de responder a unos requerimientos medioambientales), y del posible tamaño de las empresas implicadas.

\section{RESUMEN Y CONCLUSIONES}

Este artículo perseguía ofrecer cierta luz sobre cómo abordar los cambios de modelo productivo, o en la terminología de la literatura RIS3, las agendas de 
transformación económica tendentes a la diversificación y mejora productiva, de las que tan necesitada está la economía española. Para eso, se ha procedido a una revisión de la reciente literatura sobre estrategias territoriales, así como a analizar la experiencia en ese ámbito de una región que se ha caracterizado por la aplicación exitosa de tales estrategias desde comienzos de los 80: el País Vasco. Si tratamos de resumir los mensajes y lecciones que de una y otra se desprenden cabría señalar lo siguiente.

La reciente literatura sobre desarrollo económico considera que las ventajas competitivas se pueden provocar o construir y que para ello son necesarias estrategias territoriales. Por la importancia de los factores micro y de la innovación, para la competitividad, y porque el desarrollo depende principalmente de factores endógenos, las regiones se han convertido en espacios esenciales para la construcción de esas ventajas y, por lo tanto, para al desarrollo de estrategias de desarrollo.

De todos modos, como el diseño y aplicación de las estrategias territoriales es relativamente reciente, con frecuencia los decisores públicos y analistas han recurrido a la importación acrítica de bastantes conceptos y aplicaciones de la estrategia empresarial a la estrategia territorial, sin ser conscientes de que esta última difiere de aquella no solo en los objetivos (o "porqués"), sino también en las preguntas a las que debe responder para conformar el contenido (o los "qué" de la estrategia) y, especialmente, en los procesos a través de los que se diseñan e implementan (los "cómo" y "por quién").

La nueva ola de estrategias de invención e innovación para la especialización inteligente (RIS3) impulsada por la Comisión Europea en todos los países y regiones europeas se diferencia, con respecto a anteriores ejercicios de elaboración de estrategias regionales, además de por incidir en los aspectos de investigación e innovación, por considerar esenciales de dichas estrategias las prioridades temáticas o verticales, para las que resultan necesarios procesos de descubrimiento emprendedor en los que participen todos los componentes de la cuádruple hélice (el gobierno, las organizaciones del conocimiento, las empresas y la sociedad civil). Aunque su nombre pudiera hacer pensar lo contrario, las RIS3 no buscan profundizar en la especialización de los territorios en unas pocas áreas en las que ya presentaban fortalezas, sino que las RIS3 se contemplan como agendas de transformación económica que buscan la diversificación y mejora productiva, aunque eso pase por concentrar los recursos en un número relativamente reducido de prioridades, para de esa manera explotar las economías de escala y alcance que juegan en el ámbito de la innovación. Para llevar adelante esas agendas de transformación la literatura RIS3 ha identificado una serie de vías: la modernización, la expansión, la fundación radical y la combinación de actividades.

De la exitosa aplicación de este tipo de estrategias en el País Vasco desde comienzos de los años 80 se desprenderían una serie de lecciones. En primer lugar, la importancia de la continuidad en las estrategias y políticas de desarrollo, de modo 
que, aunque son apreciables diversos estadios en la aplicación de las estrategias en dicha región, cada estadio construye sobre lo avanzado en el anterior, sin hacer tabla rasa de lo realizado por los anteriores gobiernos. A pesar de los cambios habidos en los partidos que en cada momento formaban parte del Gobierno, la esencia de las estrategias de desarrollo (prioridades temáticas, políticas de ciencia y tecnología, y política de clústeres) se mantenía con pequeños cambios. Asimismo se observa que, a medida que se avanza en los estadios de desarrollo, la diversificación basada en la $\mathrm{I}+\mathrm{D}$ va ganando protagonismo, aunque la diversificación y mejora no basada en la $\mathrm{I}+\mathrm{D}$ nunca desaparezca y siga siendo un componente clave de las estrategias.

Las prioridades temáticas recogidas en la estrategia deben buscar un cierto equilibrio entre apoyar el presente y construir el futuro, equilibrio en el que los énfasis pueden diferir según el ciclo que atraviese la economía. Así, en épocas de bonanza, de abundancia de recursos y en los que la actividad y el empleo no atraviesan problemas, pueden destinarse más recursos y poner un mayor énfasis en la construcción de nuevas actividades y a largo plazo. Por el contrario, en épocas de crisis, en que el nivel de actividad y empleo se ven más amenazados, el mantenimiento de tal nivel de actividad y los aspectos más a corto plazo cobran mayor importancia. Y al igual que debe perseguirse un equilibrio entre las perspectivas de corto y largo plazo, también debe buscarse cierta proporción entre los objetivos de diversificación más incrementales o más disruptivos, entre las diferentes bases de conocimiento (más analíticas, sintéticas o simbólicas), sin perjuicio de que sobre esos equilibrios básicos existan énfasis diferentes en unas y otras.

Para la selección de las prioridades temáticas, siguiendo el ejemplo de la actual RIS3 del País Vasco, conviene considerar conjuntamente las capacidades económico-empresariales, científico-tecnológicas y las oportunidades de mercado que al territorio abren los retos sociales y las tendencias globales. En todo caso, una parte de las prioridades temáticas debe ir orientada al desarrollo de capacidades económico-empresariales en actividades que atiendan a los mercados internacionales.

Aunque en todo momento y lugar es probable que estén conviviendo varias vías de diversificación y mejora, el peso que uno y otro tipo de vías posean en la transformación productiva variarán en función del nivel de desarrollo del territorio (por ejemplo, la "modernización" es más probable que se dé en estadios de desarrollo menor, como pasó en el País Vasco en la década de los ochenta), del tipo de prioridad temática (por ejemplo, en la de biociencias es más probable que se dé la "fundación radical"), o incluso de acuerdo con las diferentes cadenas de valor o segmentos de estas (por ejemplo, es más probable la "fundación radical" en el núcleo de la cadena de valor farmacéutica -con las empresas biotecnológicas-, y la "expansión" en la cadena de valor bio-industrial o en fabricantes de otras cadenas que pasan a convertirse en proveedores de instrumental y equipos para la cadena de valor farmacéutica). 
El papel del gobierno varía asimismo según el estadio de desarrollo del territorio y las capacidades de las empresas y organizaciones del conocimiento en él existentes. Generalmente, en estadios inferiores de desarrollo, las capacidades empresariales son menores y el gobierno debe adoptar un papel más activo. Y dado el carácter transversal de los retos competitivos y de desarrollo, lo que cabe esperar es que sea Presidencia o el organismo equivalente del gobierno el que lidere la estrategia de desarrollo, especialmente en los estadios competitivos más avanzados, en que la competitividad se vuelve más compleja y multidimensional.

A medida que las capacidades empresariales se van desarrollando el gobierno debe ir dando más protagonismo a los otros actores, e incluso cambiar sus modos de intervención, dejando de tener un papel tan relevante las intervenciones vía subsidios o préstamos, y adquiriendo más relevancia su papel de regulación, validación, acreditación, prescripción y compra; o de facilitador de los espacios de colaboración y desarrollo de inversiones complementarias (por ejemplo, en recursos humanos). Sea como sea, el papel que debe desempeñar el gobierno vendrá muy marcado por su capacidad competencial y las capacidades y cualidad institucional que el mismo posea para hacer buen uso de esas competencias.

Por último, el protagonismo del gobierno es mayor en la fase del establecimiento de las prioridades temáticas territoriales, en las que se necesita una visión conjunta y sistémica y pensar no solo en el presente sino también en la construcción del futuro y la emergencia de nuevas actividades. Y el protagonismo de los agentes no gubernamentales será mayor en la concreción de tales prioridades, pues son fundamentalmente las empresas y las organizaciones del conocimiento las que poseen los conocimientos necesarios sobre mercados y tecnologías, y las organizaciones de la sociedad civil las más implicadas en los retos sociales. En la concreción y apuestas por proyectos de cada prioridad es particularmente importante que no se produzca una disociación entre el desarrollo de las capacidades científico-tecnológicas y de las económico-empresariales. El objetivo último y lo que justifica la estrategia no es el desarrollar capacidades científico-tecnológicas per se, sino el responder a las demandas económico-sociales y medioambientales, lo que implica que el apoyo a aquellas por las estrategias de desarrollo solo encuentra sentido en la medida en que son susceptibles de explotación o utilización por los agentes del territorio.

\section{BIBLIOGRAFÍA}

ARANGUREN, M. J. y otros (2012), Estrategia y política de competitividad. El caso del País Vasco, Marcial Pons, Madrid.

ASHEIM, B. y otros (2006), Constructing regional advantage. Principles, perspectives, policies, DG Research, European Commission, Brussels. 
ASHEIM, B. y GERTLER, M. (2005), "The Geography of Innovation. Regional Innovation Systems", en Fagerberg, J. y otros (eds.) The Oxford Handbook of Innovation, Oxford University Press, Oxford, pp. 291-317.

BARCA, F. (2011), "Alternative Approaches to Development Policy: Intersections and Divergences", en Seminar on Territorial Dimension of Development Policies, papers and proceedings. 18-19 July 2011, Ostróda, Poland. (pp. 45-50). Disponible en: http://www.mrr.gov.pl/english/Presidency/ Main/event_shedule/Documents/Seminar_\%20Papers_and_Proceedings. pdf

BREZNITZ, D. (2007), Innovation and the State. Political Choice and Strategies for Growth in Israel, Taiwan and Ireland, Yale University Press, New Haven \& London.

CAMAGNI, R. (2011), “'Local knowledge, national vision': challenges and prospects for the EU regional policy", en Seminar on Territorial Dimension of Development Policies, papers and proceedings. 18-19 July 2011, Ostróda, Poland. (pp. 57-63). (Descargable en: http://www.mrr.gov.pl/english/Presidency/Main/event_shedule/Documents/Seminar_\%20Papers_and_Proceedings.pdf

EUROPEAN COMMISSION (2010), Communication from the Commission to the European Parliament, the Council, the European Economic and Social Committee and the Committee of the Regions $\operatorname{COM}(2010) 553$ final. Regional Policy Contributing to smart growth in Europe 2020.

FORAY, D. (2009), "Structuring a policy response to a «Grand Challenge»", en, Knowledge for Growth. Prospect for Science, Technology and Innovation. Selected papers from Research Commissioner, Janez Potocnik's Expert Group, November 2009.

FORAY, D. (2013), "The economic fundamentals of smart specialization", Ekonomiaz, núm. 83, 2, pp. 54-78.

FORAY, D. y otros (2012), Guide to Research and Innovation Strategies for Smart Specialisations (RIS 3). European Commission, Brussels.

GILL, I. (2010), Regional development policies: Place-based or people-centred? (descargable en http://www.voxeu.org/index.php?q=node/5644)

GILL, I. (2011), Improving regional development policies. En Seminar on Territorial Dimension of Development Policies, papers and proceedings. 18-19 July 2011, Ostróda, Poland. pp. 29-34. (Descargable en: http:// www.mrr.gov.pl/english/Presidency/Main/event_shedule/Documents/Seminar_\%20Papers_and_Proceedings.pdf)

GOBIERNO VASCO (2014), RIS3 Euskadi. Prioridades estratégicas de especialización inteligente de Euskadi. Bilbao, abril.

GOBIERNO VASCO (2015), PCTI Euskadi 2020. Una estrategia de especialización inteligente. Bilbao. 
LANDABASO, M. (2012), "What public policies can and cannot do for regional development", en Cooke P. y otros (eds.) Innovation, Global Challenge and Territorial Resilience. Edward Elgar, Cheltenham, pp. 512-530.

MCCANN, P. y ORTEGA-ARGILÉS, R. (2011), "Smart Specialisation, Regional Growth and Applications to EU Cohesion Policy", Economic Geography Working Paper 2011, Faculty of Spatial Sciences, University of Groningen.

MORGAN, K. (2013), "The regional state in the era of smart specialization", Ekonomiaz, núm. 83, 2, pp. 102-125.

MOULAERT, F. y SEKIA, F. (2003), "Territorial Innovation Models: A Critical Survey”, Regional Studies, núm. 37, pp. 289-302.

NAVARRO, M. (2009), "Los sistemas regionales de innovación. Una revisión crítica”, Ekonomiaz, núm. 70, pp. 24-59.

NAVARRO, M. y otros (2011), "El análisis de benchmarking y la identificación de regiones de referencia: aplicación al País Vasco", en Navarro, M. (dir.) Indicadores de innovación y benchmarking. Reflexión y propuesta para el País Vasco, Innobasque, Zamudio, pp. 298-371.

NAVARRO, M. y otros (2012a), "Las estrategias de especialización inteligente: una estrategia territorial para las regiones", Revista Cuadernos de Gestión, núm. 12, pp. 27-49.

NAVARRO, M. y otros (2012b), "Metodología de benchmarking territorial: la necesidad de identificación de las regiones de referencia", Información Comercial Española, núm. 869, pp. 115-132.

NAVARRO, M. y otros (2014), "A holistic approach to regional strategies: The case of the Basque Country", Science and Public Policy, núm. 41, pp. 532-547.

NEFFKE, F. y otros (2011), "How do regions diversify over time? Industry relatedness and the development of new growth paths in regions", Economic Geography, núm. 87 (3), pp. 237-265.

OECD (2011a), Regions and Innovation Policy, OECD Reviews of Regional Innovation, OECD Publishing, Paris.

OECD (2011b), OECD Reviews of Regional Innovation: Basque Country, Spain. OECD Publishing, Paris.

ORKESTRA (2008), Informe de competitividad del País Vasco. Hacia una propuesta única de valor. Bilbao: Publicaciones de la Universidad de Deusto.

ORKESTRA (2013), Informe de Competitividad del País Vasco: transformación productiva para el mañana, Publicaciones Universidad de Deusto, Bilbao.

ORKESTRA (2015), Informe de Competitividad del País Vasco 2015: transformación productiva en la práctica, Publicaciones Universidad de Deusto, Bilbao. 
OUGTHON, C. M. LANDABASO y K. MORGAN (2002), "The Regional Innovation Paradox: Innovation Policy and Industrial Policy", Journal of Technology Transfer, núm. 27, pp. 97-110.

PORTER, M. E. y HEPPELMANN, J. E. (2014), "How smart, connected products are transforming competition", Harvard Business Review, núm. 92, pp. 11-64.

VALDALISO, J. M. y WILSON, J. R. (eds.) (2015), Strategies for shaping territorial competitiveness. Routdledge, Oxon-New York.

WORLD BANK (2008), World Development Report 2009: Reshaping Economic Geography. Washingthon, DC. 